\title{
IMPLEMENTASI PENGGUNAAN ALAT PERAGA KARTON BERPETAK TERHADAP HASIL BELAJAR MATEMATIKA SISWA KELAS III SDN BOJONGRENGED
}

\author{
Sifa Nursinah ${ }^{1)}$, Ina Magdalena ${ }^{2)}$, Sa'odah $^{3)}$ \\ 1) Pendidikan Guru Sekolah Dasar, Universitas Muhammadiyah Tangerang, Tangerang, Indonesia \\ E-mail: sifanursinah@gmail.com \\ 2) Pendidikan Guru Sekolah Dasar, Universitas Muhammadiyah Tangerang, Tangerang, Indonesia \\ E-mail: inapgsd@gmail.com \\ 3) Pendidikan Guru Sekolah Dasar, Universitas Muhammadiyah Tangerang, Tangerang, Indonesia \\ E-mail: saodah.umt@gmail.com
}

\begin{abstract}
This research was a descriptive qualitative with a titled implementation of cardboard display tools based on the study of mathematics in primary school with $3^{\text {rd }}$ grade students of $\mathrm{S}$ dn Bojong renged IV. The research subject are $3^{\text {rd }}$ students of Sdn Bojong renged VI This research aimed to "how to implemented of cardboard display tools based on the study of mathematics in primary school with subjects are $3^{\text {rd }}$ grade students of Sdn Bojong renged VI.? The method of this research are qualitative data which is the instruments used in this study are observation, interviews, and documentation. The research objective is that the implementation of the use of teaching aids can provide concrete scientific contributions to the implementation of learning outcomes, especially in mathematics. The data was then analyzed using qualitative descriptive.Based on the results of the study, it can be concluded that both the process assessments and the learning assessments made by submitting post tests are improvement in students studies. In the last data, Students reached 34,78 percent which is just 8 of 23 children who have been got the same grade with a value of test results above KKM and 65,22 percent which is just 15 of 23 children who have been got below KKM. The minimum criteria (KKM) of this lesson is 60 . The students who have a score below KKM just 10 of 23 children that be sampled. The results of students in math studies from the post-test in fraction sub are increase.
\end{abstract}

Keywords: implementation of object use derived from math study

\section{PENDAHULUAN}

Peningkatan mutu pendidikan merupakan salah satu unsur yang sangat penting dalam upaya meningkatkan kualitas sumber daya manusia. Kegiatan yang utama dalam menentukan keberhasilan proses pendidikan adalah kegiatan pembelajaran.

Untuk menciptakan proses pembelajaran yang berkualitas, guru sering kali menemukan kesulitan dalam memeberikan materi pembelajaran matematika terkait sifatnya yang abstrak. Matematika yang bersifat abstrak tersebut merupakan kesulitan tersendiri yang harus dihadapi peserta didik. Konsep- konsep matematika dapat dipahami dengan mudah bila bersifat konkret. Karena pengeajaran matematika harus dilakukan secara bertahap. Matematika harus dimulai dari tahapan konkret. Lalu diarahkan pada tahapan semi konkret, dan pada akhirnya siswa dapat berpikir dan memahami matematika secara abstrak.

Undang-undang Nomor 20 Tahun 2003 tentang Sistem Pendidikan Nasional Bab II Pasal 3, "Pendidikan bertujuan untuk mengembangkan potensi peserta didik seutuhnya agar menjadi manusia yang beriman dan bertakwa kepada Tuhan Yang Maha Esa, berakhlak mulia, sehat, berilmu, cakap, kreatif, mandiri, dan menjadi warga negara yang demokratis serta bertanggung jawab". ${ }^{10}$ Matematika sebagai salah satu dari cakupan kelompok mata pelajaran yang berpikir kritis, kreatif dan mandiri.

Disisi lain proses pembelajaran dari mata pelajaran Matematika yang dilaksanakan pada tanggal 03 Desember 2019 dengan materi "Pecahan" yang dilaksanakan di sekolah SDN Bojongrenged VI terdapat fakta-fakta sebagai berikut : Kurangnya minat belajar siswa terhadap pembelajaran matematika, sehingga cenderung pasif dalam belajar, Proses pembelajaran matematika kurang menarik dan 
terlalu monoton, Siswa mengalami kesulitan dalam memahami materi tentang "Pecahan", tidak mau bertanya ketika diberi kesempatan untuk bertanya jika ada yang belum dimengerti, Bila diberi pertanyaan siswa tidak mau mengangkat tangan untuk menjawab, dan setelah diadakan evaluasi, perolehan nilai siswa lebih separuhnya $(65,22 \%)$ masih di bawah Kriteria Ketuntasan Minimum (KKM) . Data perolehan nilai siswa menunjukan bahwa dari 23 siswa SD kelas III yang mendapatkan nilai sama atau di atas KKM hanya 8 siswa yaitu $34,78 \%$, dan yang mendapatkan nilai di bawah KKM 15 siswa yaitu 65,22\%. Adapun KKM dari mata pelajaran Matematika adalah 60. Melihat kenyataan tersebut, ada sesuatu yang kurang dilakukan guru dalam mengajar, untuk itu harus dicari solusi pemecahan masalah tersebut. Menyadari itu semua peneliti mencoba memikirkan upaya yang harus dilakukan dalam meningkatkan prestasi belajar siswa. Peneliti berupaya untuk mengatasi proses pembelajaran Matematika dengan media pembelajaran konversional yang diharapkan dengan alat peraga tersebut dapat meningkatkan hasil belajar siswa. Alat peraga adalah segala sesuatu yang dapat digunakan untuk menyatakan pesan merangsang pikiran, perasaan, dan perhatian dan kemauan siswa sehingga dapat mendorong proses belajar (Ali, 1989). Menurut Reseffendi (1992), alat peraga adalah alat yang menerangkan atau mewujudkan konsep matematika, sedangkan pengertian alat peraga matematika menurut Pramudjono(1995), adalah benda konkret yang dibuat, dihimpun atau disusun secara sengaja digunakan untuk membantu menanamkan atau mengembangkan knsep matematika. ${ }^{8}$

Media pembelajara adalah alat yang dapat membantu proses belajar mengajar dan berfungsi untuk memperjelas makna pesan yang disampaikan, sehingga dapat mencapai tujuan pembelajaran dengan lebih baik dan sempurna. ${ }^{4}$

Secara lebih khusus, pengertian media dalam proses belajar mengajar cenderung diartika sebagai alat-alat grafis, photografis, atau elektronis untuk menangkap, memperoses, dan meyusun kembali informasi visual atau verbal ${ }^{2}$.

Menurut Yonandi 2010 Matematika adalah bahasa ensesial yang tidak hanya alat berpikir, menemukan rumus, menyelesaikan masalah, atau menyimpulkan saja, namun matematika juga memiliki nilai yang tak terbatas untuk menyatakan beragam ide secara jelas, teliti dan tepat. Matematika dan belajar matematika adalah jantungnya kegiatan social manusia misalnya, dalam pembelajaran matematika interaksi antara guru dan siswa, antara siswa dan siswa, antara bahan pelajaran matematika dan siswa adalah faktor-faktor penting dalam memajukan potensi siswa. ${ }^{3}$

Hasil belajar sebagai mana telah dijelaskan diatas meliputi pemahaman konsep (aspek kognitif), keterampilan proses (aspek psikomotor), dan sikap siswa (aspek afektif) ${ }^{7}$ Menurut winkel, 1998. h. 51 Hasil belajar adalah perubahan yang mengakibatkan manusia berubah dalam sikap dan tingkah lakunya. ${ }^{5}$ Hasil belajar ranah psikomotor dikemukakan oleh simpson (1956) yang menyatakan bahwa hasil belajar psikomotor ini tampak dalam bentuk keterampilan dan kemampuan bertindak individu ${ }^{1}$.

Bilang rasional atau pecahan termaksud materi yang sulit dipahami anak diantara bilang lainya. Berbagai upaya dapat dilakukan untuk membantu anak, diantaranya menyajikan masalah secara kontekstual menggunakan alat peraga manipulative. Disamping itu pecahan perlu disampaikan dalam bentuk hands on experience, belajar kelompok atau belajar dengan bermain adapun alat peraga yang digunakan adalah karton berpetak berdasarkan latar belakang belakang di atas, maka penulis telah merumuskan masalah sebagai berikut: Bagaimana implementasi penggunaan alat peraga karton berpetak terhadap hasil belajar matematika siswa kelas III SDN Bojongenged VI?

Berdasarkan dengan rumusan masalah di atas, maka tujuan penelitian ini adalah untuk mengetahui gambaran Implementasi tentang penggunaan alat peraga karton berpetak terhadap hasil belajar matematika Siswa Kelas III di SDN Bojongreged VI Kecamatan Teluknaga Kabupaten Tangerang.

\section{METODE}

Penelitian ini menggunakan penelitian kualitatif dengan jenis metode penelitian deskriptif kualitatif. Karena Penelitian ini dilakukan untuk memecahkan masalah pembelajaran dikelas. Penelitian ini termasuk penelitian deskriptif, sebab menggambarkan bagaimana suatu teknik pembelajaran diterapkan dan bagaimana hasil yang diinginkan dapat dicapai. Adapun jenis data yang digunakan dalam penelitian ini adalah data kualitatif, yaitu data yang disajikan dalam bentuk kata verbal bukan dalam bentuk angka, yang termaksud data kualitatif dalam penelitian ini yaitu gambaran tetang implementasi penggunaan alat peraga karton berpetak dalam pembelajaran matematika.

Tabel 1 Teknik pengumpulan data

\begin{tabular}{|c|c|c|}
\hline No & $\begin{array}{c}\text { Teknik } \\
\text { penggumpulan } \\
\text { data }\end{array}$ & Fokus \\
\hline 1 & Observasi & $\begin{array}{l}\text { Implementasi } \\
\text { penggunaan alat } \\
\text { peraga karton } \\
\text { berpetak di SDN } \\
\text { bojongrenged VI }\end{array}$ \\
\hline 2 & Wawancara & $\begin{array}{l}\text { Implementasi } \\
\text { penggunaan alat } \\
\text { peraga karton } \\
\text { berpetak di SDN } \\
\text { bojongrenged VI }\end{array}$ \\
\hline 3 & Dokumen & $\begin{array}{l}\text { foto alat peraga dan } \\
\text { data nilai siswa }\end{array}$ \\
\hline
\end{tabular}

Validitas adalah suatu ukuran yang menunjukan tingkat kevalidan atau kesahihan suatu instrumen. Prinsip validitas adalah pengukuran atau pengamatan yang berarti prinsip keandalan instrumen dalam mengumpulkan data. Instrumen harus dapat mengukur apa yang seharusnya diukur. Suatu instrumen penelitian harus valid agar hasilnya dapat dipercaya. 


\section{HASIL DAN PEMBAHASAN}

\begin{tabular}{clcc}
\multicolumn{4}{c}{ Tebel 2 Nilai Siswa } \\
\hline \multirow{2}{*}{ No. } & \multirow{2}{*}{ NAMA } & \multicolumn{2}{c}{ Nilai } \\
\cline { 3 - 4 } & & Pra penelitian & Post test \\
\hline 1 & AAS & 40 & 70 \\
2 & AP & 45 & 70 \\
3 & AS & 45 & 55 \\
4 & AKN & 50 & 60 \\
5 & FZR & 50 & 80 \\
6 & FP & 45 & 85 \\
7 & SR & 30 & 70 \\
8 & KP & 50 & 85 \\
9 & MB & 45 & 60 \\
10 & MP P & 45 & 70 \\
\hline
\end{tabular}

\begin{tabular}{lccc}
\multicolumn{4}{c}{ Tabel 3. Persentase ketuntasan } \\
\hline Kualifikasi & $\begin{array}{c}\text { Tingkat } \\
\text { ketuntasan }\end{array}$ & $\begin{array}{c}\text { frek } \\
\text { uen } \\
\text { si }\end{array}$ & $\%$ \\
\hline Tuntas & $\geq 60$ & 9 & $90 \%$ \\
Tidak & $\leq 60$ & 1 & $10 \%$ \\
Tuntas & & 10 & $100 \%$ \\
\hline \multicolumn{2}{c}{ Jumlah } & &
\end{tabular}

Dari 10 siswa, siswa yang memperoleh nilai diatas KKM berjumlah 9 dan siswa yang nilainya dibawah KKM berjumlah 1, terjadi peningkatan yang signifikan, dibandingkan sebelum dilakukan perbaikan, Peningkatan terlihat dari jumlah siswa yang memiliki nilai di atas KKM 9 siswa, maka dalam perbaikan pembelajaran ini sudah bisa dikatakan maksimal.

\section{KESIMPULAN}

1. Dalam implementasi penggunaan alat peraga karton berpetak terhadap hasil belajar matematika siswa kelas III SDN Bojongrenged VI terjadi peningkatan dengan persiapan pembelajaran yang terencana serta pemberian post test beserta latihan yang dilakukan guru dapat meningkatkan nilai hasil belajar siswa.

2. Dalam implementasi penggunaan alat peraga karton berpetak terhadap hasil belajar matematika siswa kelas III SDN Bojongrenged VI Guru Menggunakan metode ekspositori yaitu metode pembelajaran yang digunakan dengan memberikan keterangan terlebih dahulu mengenai definisi, prinsip, dan konsep materi pelajaran serta memberikan contoh- contoh latihan pemecahan masalah dalam bentuk ceramah, demonstrasi, tanya jawab, dan penugasan.

3. Penggunaan alat peraga yang menarik dan relevan dengan materi pembelajaran menumbuhkanminat belajar siswa dan menghindari kejenuhan.

4. Peningkatan penguasaan materi pembelajaran pada siswa dapat diupayakan melalui penyampaian materi yang lebih menarik, variatif dan spesifik, serta melibatkan siswa dalam proses pembelajaran.

\section{DAFTAR PUSTAKA}

[1] Arsyad, A. (2019). Media Pembelajaran. Depok: PT Rajawali Pers.

[2] Hendriana, H., \& Soemarno, U. (2014). Penilaian Pembelajaran

Matematika. Bandung: PT. Refika Aditama.

[3] Kustandi, C. \& Sujipto, B. (2013). Media Pembelajaran Manual dan Digital. Bogor: Ghalia Indonesia.

[4] Purwanto. (2013). Evaluasi Hasil Belajar. Yogyakarta: PUSTAKA PELAJAR.

[5] Slamet. (2018). Belajar dan faktor-faktor yang mempengaruhi. Jakarta : PT RINEKA CIPTA.

[6] Susanto, A. (2013). Teori Belajar \& Pembelajaran di Sekolah Dasar Jakarta: PRENNADAMEDIA GROUP.

[7] Sundayana, R. (2018). Media dan Alat Peraga dalam Pembelajaran Matematika. Bandung: Alfabeta.

[8] Torar, Lexy. (2010). Evaluasi Matematika Sekolah Dasar. Jakarta: TRANS

MANDIRINABADI.

[9] Undang-undang Nomor 20. (2003) tentang Sistem Pendidikan Nasional Bab II Pasal 3.

[10] Yurniwati. (2019). Pembelajaran Aritmatika di Sekolah Dasar. Bandung: PT REMAJA ROSDAKARYA 